\title{
Precursor Cell Biology and the Development of Astrocyte Transplantation Therapies: Lessons from Spinal Cord Injury
}

\author{
Mark Noble • Jeannette E. Davies • \\ Margot Mayer-Pröschel • Christoph Pröschel • \\ Stephen J. A. Davies
}

Published online: 15 September 2011

(C) The Author(s) 2011. This article is published with open access at Springerlink.com

\begin{abstract}
This review summarizes current progress on development of astrocyte transplantation therapies for repair of the damaged central nervous system. Replacement of neurons in the injured or diseased central nervous system is currently one of the most popular therapeutic goals, but if neuronal replacement is attempted in the absence of appropriate supporting cells (astrocytes and oligodendrocytes), then the chances of restoring neurological functional are greatly reduced. Although the past 20 years have offered great progress on oligodendrocyte replacement therapies, astrocyte transplantation therapies have been both less explored and comparatively less successful. We have now developed successful astrocyte transplantation therapies by pre-differentiating glial restricted precursor (GRP) cells into a specific population of GRP cell-derived astrocytes (GDAs) by exposing the GRP cells to bone morphogenetic protein-4 (BMP) prior to transplantation. When transplanted into transected rat spinal cord, rat and human GDAs ${ }^{\text {BMP }}$ promote extensive axonal regeneration, rescue neuronal cell survival, realign tissue structure, and
\end{abstract}

Christoph Pröschel and Stephen J. E. Davies contributed equally to this review.

Electronic supplementary material The online version of this article (doi:10.1007/s13311-011-0071-z) contains supplementary material, which is available to authorized users.

M. Noble $(\triangle) \cdot$ M. Mayer-Pröschel $\cdot$ C. Pröschel

University of Rochester Stem Cell and Regenerative Medicine Institute and Department of Biomedical Genetics, University of Rochester School of Medicine and Dentistry,

Rochester, NY 14642, USA

e-mail: mark_noble@urmc.rochester.edu

J. E. Davies $\cdot$ S. J. A. Davies

Department of Neurosurgery, University of Colorado, Denver,

Anschutz Medical Campus,

Aurora, CO 80045, USA restore behavior to pre-injury levels on a grid-walk analysis of volitional foot placement. Such benefits are not provided by GRP cells themselves, demonstrating that the lesion environment does not direct differentiation in a manner optimally beneficial for the restoration of function. Such benefits also are not provided by transplantation of a different population of astrocytes generated from GRP cells exposed to ciliary neurotrophic factor (GDAs ${ }^{\mathrm{CNTF}}$ ), thus providing the first transplantation-based evidence of functional heterogeneity in astrocyte populations. Moreover, lessons learned from the study of rat cells are strongly predictive of outcomes using human cells. Thus, these studies provide successful strategies for the use of astrocyte transplantation therapies for restoration of function following spinal cord injury.

Keywords Glial-restricted precursor cells - Glial precursor cell-derived astrocyte $\cdot$ Spinal cord injury $\cdot$ Regeneration . Astrocyte transplantation therapy Astrocyte heterogeneity

$\begin{array}{ll}\text { Abbreviations } \\ \text { AMPA } & \begin{array}{l}\text { a-amino-3-hydroxy-5-methyl-4-isoxazolepropionic } \\ \text { acid }\end{array} \\ \text { AQP4 } & \begin{array}{l}\text { aquaporin } 4 \\ \text { BMP }\end{array} \\ \text { bone morphogenetic protein-4 } \\ \text { CNS } & \begin{array}{l}\text { central nervous system } \\ \text { CNTF }\end{array} \\ \text { ciliary neurotrophic factor } \\ \text { CSPG } & \text { chondroitin sulfate proteoglycan } \\ \text { DFL } & \text { dorsolateral funiculus } \\ \text { ESC } & \text { embryonic stem cell } \\ \text { FGF } & \text { fibroblast growth factor } \\ \text { GDA } & \text { GRP-derived astrocyte } \\ \text { GDNF } & \text { glial-derived neurotrophic factor } \\ \text { GFAP } & \text { glial fibrillary acidic protein } \\ \text { GLT-1 } & \text { glutamate transporter 1 }\end{array}$




$\begin{array}{ll}\text { GRP } & \text { glial precursor cell } \\ \text { hGPC } & \text { human glial precursor cell } \\ \text { iPSC } & \text { induced pluripotent stem cell } \\ \text { mRNA } & \text { messenger RNA } \\ \text { NSC } & \text { neuroepithelial stem cell } \\ \text { O-2A } & \text { oligodendrocyte/type-2 astrocyte } \\ \text { OMIM } & \text { Online Mendelian Inheritance in Man } \\ \text { SCI } & \text { spinal cord injury } \\ \text { VWM } & \text { vanishing white matter disease }\end{array}$

\section{Introduction}

Replacement of neuronal populations in the injured or diseased central nervous system (CNS) is currently one of the most popular therapeutic goals, but if neuronal replacement is attempted in the absence of appropriate supporting cells (i.e., astrocytes and oligodendrocytes), then the chances of restoring neurological function are greatly reduced. The requirement for myelination of CNS fibers to achieve normal impulse conduction has long been recognized, and myelin deficiency is thought to be responsible for neurological dysfunction in a wide range of genetic diseases, chronic degenerative conditions, and in traumatic injury to the CNS. However, it is now widely recognized that the astrocyte is also a fundamental contributor to normal CNS function, with roles in providing substrates for axonal outgrowth, regulating dendritic arborization, promoting synaptic function, producing survival factors for neurons and oligodendrocytes and mitogens for progenitor cells, inducing formation of the blood-brain barrier, maintaining the metabolic microenvironment of the CNS, sequestering neurotransmitters and, in some situations, promoting recovery after traumatic injury (to name just a few) [1-24]. Thus, in seeking to repair the adult CNS, the presence of functional astrocytes is likely to be critically important in restoring normal CNS function.

Strategies for oligodendrocyte replacement with populations of purified CNS progenitor cells have been pursued for more than 20 years $[25,26]$, have provided clear functional benefit [27-29], and have been associated recently with notable successes in human oligodendrocyte replacement in experimental animals [30-33]. Oligodendrocyte replacement has been conducted using lineagerestricted progenitor cells directly isolated from the developing or mature CNS of rodents, dogs, and humans, with neuroepithelial stem cells and with oligodendrocyte progenitor cells derived from embryonic stem cells of murine and human origin [25-38].

In contrast with progress in the repair of damage to myelin by transplanting cells capable of generating oligodendrocytes, replacement of astrocytes as a therapeutic strategy has been far less explored. Transplantation carried out using astrocytes generated as purified cell populations from the developing rodent CNS has provided marginal benefit in animal models of brain and spinal cord injury (SCI). Therefore, until recently, transplantation of astrocytes has not provided the level of benefit obtained by transplantation of other cell types. However, more recently, transplants of distinct types of astrocytes into the SCI have demonstrated both the utility of astrocyte transplants and the functional heterogeneity of astrocyte subtypes [39-41].

\section{Astrocyte Dysfunction Occurs in Multiple Neurological Diseases and in Traumatic Injury to the CNS}

The lack of progress in the development of astrocyte transplantation therapies stands in striking contrast with progress in understanding the importance of astrocytic dysfunction in contributing to a wide range of CNS disorders. The first indications that abnormalities in astrocyte function may contribute to genetic diseases of the CNS, paradoxically came from studies on two leukodystrophies (diseases characterized by abnormal development and/or degeneration of the myelinated white matter tracts of the CNS). Studies on the mutations responsible for Alexander disease, a sporadically occurring leukodystrophy that appears in the absence of familial history, localized these mutations in 2001 to the gene for glial fibrillary acidic protein (GFAP), one of the major intermediate filament proteins in astrocytes [42-45]. Thus, in this disease, a dominant mutation in an astrocytic cytoskeletal protein can cause neurological disease. Four years later, studies on Vanishing White Matter disease (Online Mendelian Inheritance in Man (OMIM) \#603896, a recessively inherited leukodystrophy) revealed that CNS precursor cells isolated from a child who had died of this disease had a greatly reduced ability to generate astrocytes in response to signaling molecules known to induce differentiation into such cells, and those astrocytes that were generated were morphologically abnormal [46]. Moreover, genetic mimicking of the dysfunction in EIF2B5 ( 1 of the 5 ribosomal regulatory proteins for which mutations can cause Vanishing White Matter disease) in normal human glial precursor cells compromised their ability to generate astrocytes in vitro. In vivo, lesions in the CNS of children with this disease show a remarkable lack of astrocytes, in contrast with the gliotic response that is characteristic of virtually all other CNS lesions.

In subsequent years, dysfunction of astrocytes has also been suggested to be of importance in models of amyotrophic lateral sclerosis [47], forebrain ischemic injury [48], epileptic seizures [49], Huntington's disease [50, 51], tuberous sclerosis [52], Rett syndrome [53], and Parkinson's disease [54, 55]. The types of changes in 
astrocyte function thought to be important in these diseases are varied, and include putative secretion of toxic agents [47], organic cation transport [54], changes in astroglial AMPA-class glutamate receptors [49, 56], or gap junction coupling [52]. Thus, it appears that multiple interruptions to normal astrocyte function can contribute to the pathogenesis of a variety of neurological diseases.

There are also astrocytic functions that appear to have negative outcomes in CNS disease, these being the generation of astro-glial scar tissue after CNS injury. It has long been known that reactive astrocytes within glial scar tissue contribute to the failure of axon regeneration in sites of traumatic brain injury or SCI [57-61], and may, at least theoretically, inhibit oligodendrocyte progenitor cell entry into the lesion site [62]. Multiple inhibitory molecules have been identified that are expressed by reactive astrocytes in traumatic CNS injuries, including a variety of chondroitin sulfate proteoglycans that inhibit axon growth [59,63-68]. It is not known whether other functions of healthy astrocytes are compromised when scar tissue is generated, but just the formation of axon growth inhibitory glial scar itself represents another means by which alterations in the function of astrocytes can compromise neurological recovery.

\section{Glial Restricted Precursor Cells as a Potential Source of Astrocytes for Transplantation}

The recognition that astrocyte dysfunction may play an important role in a wide range of neurological disorders raises the question of whether astrocyte transplantation could be of therapeutic value in treating the injured or diseased human CNS. Tests of this possibility in animal models, however, have not been promising until recently. Despite the ability of postnatal cortex-derived astrocytes to provide an effective substrate for promoting axonal outgrowth in vitro $[1-3,6,69,70]$, in terms of promoting functional recovery, transplantation of astrocytes has given rise to mixed results, at best, in animal models of Parkinson's disease [71, 72] and has provided only modest benefit in experimental spinal cord injuries [73].

One possible reason for these modest outcomes in previous astrocyte transplantation studies may be the methods used to isolate these cells from the immature CNS. Although astrocyte purification has been in use for almost 30 years [1, 74, 75], populations of astrocytes maintained in vitro for even relatively short periods of time soon express inhibitory properties such as those seen in glial scar tissue [76]. A central challenge, therefore, in the development of astrocyte transplantation therapies is the identification of the means of obtaining pure populations of these cells, in ways that do not suppress their beneficial attributes. Thus, it has become clear that a different approach to astrocyte generation is required to test the potential of astrocyte replacement therapies for treatment of the injured and diseased CNS.

Our approach to astrocyte generation relies on generating these cells directly from an embryonic glial-restricted progenitor (GRP) cell that we have proposed is the earliest glial-restricted ancestor of the various glial cell populations of the spinal cord [77, 78]. GRP cells are first observed in the embryonic day 12 to 13 rat or mouse spinal cord, and appear to be the first glial-restricted cell populations generated from neuroepithelial stem cells $[79,80]$ (summarized in Fig. 1). GRP cells appear to be directly derived from neuroepithelial stem cells (NSCs), and appear at the same developmental stage at which NSCs generate parallel populations of neuron-restricted precursor cells [81].

Both GRP cells and NRP cells can be directly isolated from the developing rat spinal cord and grown as purified populations [81]. Freshly isolated cells exhibit the same lineage restrictions as those cells derived from NSCs in vitro. Clonal studies have demonstrated that GRP cells retain their tri-potential nature even after weeks of in vitro expansion and several serial re-clonings [80], and GRP cells also exhibit these same restrictions following transplantation in vivo. GRP cells generate both oligodendrocytes and astrocytes following transplantation into brain or spinal cord [39, 41, 82-91], and do not generate neurons even when they migrate into such neurogenic zones as the

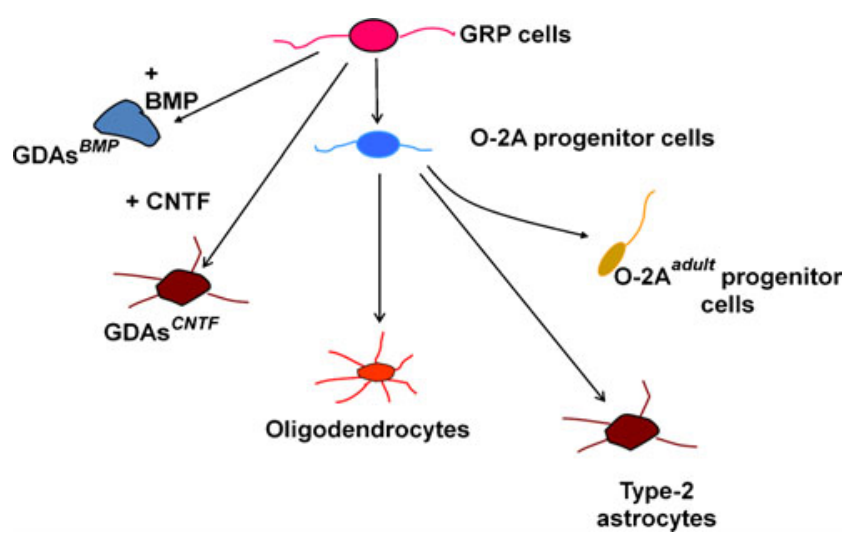

Fig. 1 Schematic representation of the lineage relationships of the cell types relevant to this review. Neuroepithelial stem cells (not shown) give rise to glial-restricted precursor (GRP) cells. GRP cells in turn can give rise to two different kinds of astrocytes depending on the signaling molecule to which they are exposed. GRP cells also can generate oligodendrocyte-type-2 astrocyte (O-2A) progenitor cells. $\mathrm{O}-2 \mathrm{~A}$ progenitor cells in turn are the ancestors of oligodendrocytes, but can also give rise to an adult-specific variant of the O-2A progenitor cell. O-2A progenitor cells (referred to in the text as O-2A/OPCs) also can give rise to type- 2 astrocytes, which have may antigenic characteristics in common with astrocytes generated by exposing spinal cord GRP cells to ciliary neurotrophic factor (GDAs ${ }^{\mathrm{CNTF}}$ ) 
rostral migratory stream and olfactory bulb [86]. Cells with GRP cell-like characteristics can be isolated from the embryonic human [41, 92], rat, and mouse spinal cords [80], and can be generated from embryonic stem cells [93] or neural epithelial stem cells [79] from both the murine as well as the human system [94]. It is important to add a cautionary note; however, to say that we consider it premature to suggest that the human cells are fully identical with the rodent-derived cells in their biology. Nonetheless, there are remarkable similarities, as will be illustrated when we discuss our work on transplantation of human glial precursor cell-derived astrocytes.

GRP cells differ from the much more widely studied oligodendrocyte/type-2 astrocyte progenitor cell (also referred to as an oligodendrocyte precursor cell, and here abbreviated as an $\mathrm{O} 2 \mathrm{~A} / \mathrm{OPC}$ ), and these two populations clearly represent distinct cell types [78, 80]. O-2A/OPCs are only able to generate one antigenic population of astrocytes, a population of A2B5 plus GFAP plus type-2 astrocytes, originally referred as type-2 astrocytes [95, 96]. Spinal cord-derived GRP cells, in contrast, can generate two different astrocyte populations: type- 2 astrocytes and a population of A2B5-negative/GFAP + cells that were originally given the name of type- 1 astrocytes $[95,97]$. It is important to note that GRP cell populations isolated from the embryonic telencephalon (tGRP cells) differ yet again in their differentiation potential. Studies on tGRP cells, in fact, offer an important lesson in the importance of not drawing premature conclusions about astrocyte phenotypes. Whether tGRP cells are exposed to BMP or CNTF, they generate a population with the morphological phenotype and A2B5-negative antigenic phenotype of type-1 astrocytes [98]. Nonetheless, our ongoing studies demonstrate functional differences in these two astrocyte populations.

Freshly isolated GRP cells from the E13.5 rat spinal cord or the E15 telencephalon are dependent on exposure to fibroblast growth factor-2 (FGF-2) for both their survival and their division, whereas division and survival of $\mathrm{O}-2 \mathrm{~A} /$ OPCs can be promoted by platelet-derived growth factor (PDGF) and other chemokines. Consistent with this difference in chemokine-response patterns, GRP cells freshly isolated from the E13.5 spinal cord do not express receptors for PDGF, although they do express such receptors with continued growth in vitro or In vivo. These populations also differ in their response to inducers of differentiation. For example, exposure of GRP cells to the combination of FGF-2 and ciliary neurotrophic factor (CNTF) induces these cells to differentiate into astrocytes (primarily expressing a morphological and antigenic phenotype of type- 2 astrocytes for spinal cord GRP cells and type-1 astrocytes for tGRP cells [80, 98]). In contrast, exposure of $\mathrm{O}-2 \mathrm{~A} / \mathrm{OPCs}$ to $\mathrm{FGF}-2$ plus CNTF promotes the generation of oligodendrocytes [99-101]. Moreover, the behavior of $\mathrm{O}-2 \mathrm{~A} / \mathrm{OPCs}$ and GRP cells following transplantation is strikingly different. The ability of both spinal cord GRP cells and tGRP cells to readily generate astrocytes following transplantation into the adult CNS stands in striking contrast to the behavior of primary O$2 \mathrm{~A} / \mathrm{OPCs}$, which appear to be primarily committed to the generation of oligodendrocytes in such situations [102104]. This may not be an absolute difference, however, as there appears to be conditions (discussed as follows) in which O-2A/OPCs will generate astrocytes following injury, and their capacity to do so after transplantation is going to require more careful analyses.

It currently appears that GRP cells and O-2A/OPCs represent a developmental transition, with the second population appearing from first as development proceeds. in vitro studies showed that GRP cells give rise to O-2A progenitor cells and that it was a seemingly necessary step in the generation of oligodendrocytes from GRP cells [105], suggesting that the sequential appearance of these two progenitor cell populations during CNS development represents stages of differentiation within a single glial lineage [78].

\section{Astrocytic Pre-Differentiation is Required to Promote Regeneration Using Cells of the GRP Cell Lineage}

The ability to isolate and grow large quantities of GRP cells in vitro enabled us to generate pure populations of astrocytes without requiring extended in vitro growth of the astrocytes themselves. This enabled a direct comparison of the usefulness of GRP cells and glial restricted precursorderived astrocytes (GDAs) in promoting recovery from SCI.

Despite the apparent role of GRP cells in generating the glial cells of the developing spinal cord, transplantation of these cells only provided modest benefit when transplanted into experimental lesions of the spinal cord. When transplanted into the contused cord, these cells showed some ability to reduce proteoglycan deposition in the adjacent host tissue [85]. More recently, transplantation of rat GRP cells has been shown to improve some autonomic functions when combined with modulation of cyclic AMP (cAMP) levels, but failed to provide improvements in tests of locomotor recovery [88].

SCI experiments conducted through collaboration between our research teams in Denver and Rochester, however, showed that in contrast with transplantation of GRP cells themselves, transplantation of GRP-derived astrocytes generated by exposure of embryonic GRP cells to bone morphogenetic protein-4 (GDAs ${ }^{\mathrm{BMP}}$ ) promotes marked benefit in SCI [39]. GDA ${ }^{\text {BMP }}$ transplantation 
promoted robust behavioral recovery in adult rats with unilateral dorsolateral funiculus (DLF) lesions to the extent that transplanted animals became statistically indistinguishable from uninjured animals in the grid-walk/horizontal ladder test of volitional foot placement (Fig. 2). In addition, transplantation of GDAs ${ }^{\mathrm{BMP}}$ also suppressed the expression of axon growth inhibitory chondroitin sulfate proteoglycans (CSPGs) at sites of injury, provided neuroprotection to neurons of the red nucleus, and promoted extensive regeneration of injured dorsal column axons into the injury center and out into white matter beyond the injury site. $\mathrm{GDA}^{\mathrm{BMP}}$ transplantation also induced a striking realignment of injured tissue, in which the normally misaligned structure of the glial scar was replaced by parallel arrays of astrocyte processes linearly organized along the longitudinal axis of the spinal cord. Regeneration of endogenous dorsal column axons was equally robust, with $66 \%$ of axons reaching injury centers and $39 \%$ of axons having grown extensive distances within distal white matter in just 8 days. Further tests with adjacent micro-transplants of adult mouse DRG neurons expressing green fluorescent protein, a technique that enabled us to unambiguously distinguish between axonal regeneration and sprouting, confirmed the robust support of axon growth across spinal cord injuries provided by GDAs ${ }^{\text {BMP }}$. Thus, this single modality therapy provides (and generally exceeds) benefits otherwise only obtained with approaches that have combined cell-based therapies with biomaterials, genetic modification of transplanted cells, and/or co-administration of bioactive proteins or pharmacological agents.

As seen in previous studies of contusion SCI [88, 106, 107], GRP cell transplantation failed to provide significant regenerative or behavioral benefit in transection injuries, despite evidence of having generated GFAP-positive cells within injury sites. Taken together, these results demonstrate that controlled pre-differentiation of GRP cells into specific GDAs before transplantation into SCIs is required to optimize outcomes. This is a particularly important concept, as it may dictate the way in which scientists and clinicians should approach the use of stem/progenitor cells to maximize tissue repair, with the recognition that transplantation of undifferentiated stem or progenitor cells may not be the optimum means of using these cells, whereas transplantation of their pre-differentiated derivatives may provide far greater benefit.

The experiments on transplantation of GDAs ${ }^{\text {BMP }}$, thus overturn the prevailing scientific notion that astrocyte transplantation therapies do not provide significant benefit in the treatment of SCI. Critically, these experimental outcomes also directly challenge the view that after transplantation of undifferentiated stem or progenitor cells, the injured tissue is capable of providing the appropriate signals to direct precursor cells along cell differentiation pathways that are useful for repairing the traumatically injured spinal cord.

\section{Transplantation of the Wrong Astrocyte Population Fails to Promote Regeneration}

The next question that must be asked regarding the development of astrocyte transplantation therapies is whether all astrocytes generated from GRP cells are equivalent in their ability to promote repair. GRP cells are of particular interest in regard to addressing this question due to their earlier discussed ability to generate 2 distinct populations of astrocytes.

The astrocytes generated from spinal cord GRP cells as a consequence of exposure to ciliary neurotrophic factor (GDAs ${ }^{\mathrm{CNTF}}$ ), or to other agonists for gp130 receptors, exhibit a very different phenotype from GDAs ${ }^{\text {BMP }}$. These two populations differ in antigenic phenotype, morphology, expression of FGF receptor-3 and expression of axon growth inhibitory proteoglycans, such as neurocan and phosphacan $[40,80]$.

To determine the usefulness of GDAs ${ }^{\mathrm{CNTF}}$ in SCI repair, we transplanted these cells into transection injuries of the spinal cord as in our studies on GDAs ${ }^{\mathrm{BMP}}$ and analyzed axon regeneration, neuroprotection, and behavioral recovery (Fig. 3). In these experiments, homogenous populations of embryonic (E13.5) rat GRP cells were cultured as for the generation of GDAs ${ }^{\mathrm{BMP}}$, except that CNTF was added to cultures for 1 week to induce differentiation into pure populations of GDAs ${ }^{\mathrm{CNTF}}$. These astrocytes were then collected and transplanted into acute adult rat dorsal column SCIs in an identical fashion to that previously used for transplantation of the GDAs ${ }^{\text {BMP }}$. The ability of the intrainjury transplanted GDAs ${ }^{\mathrm{CNTF}}$ to support axon growth was determined by analysis of the regeneration of severed endogenous ascending dorsal column axons labeled with biotinylated dextran amine.

In contrast with the effects of GDAs ${ }^{\text {BMP }}$, we found that GDAs ${ }^{\mathrm{CNTF}}$ failed to provide significant benefit in the repair of SCI [40]. The GDAs ${ }^{\text {CNTF }}$ did not provide supportive bridges for growth of ascending dorsal column axons across sites of injury. Moreover, the transplanted GDAs $^{\text {CNTF }}$ failed to suppress host astrogliosis within injury margins and also failed to cause linear realignment of host astrocytes. In contrast, transplants of $\mathrm{GDAs}^{\mathrm{BMP}}$ once again suppressed astrogliosis and caused extensive linear realignment of host astrocytes. When transplanted to transection injuries of dorsolateral funiculus white matter in which axons of the rubrospinal tract 
were severed, GDAs ${ }^{\mathrm{CNTF}}$ also failed to rescue injured neurons of the red nucleus.

Behavioral analysis of $\mathrm{GDA}^{\mathrm{CNTF}}$-transplanted animals was consistent with the lack of axonal regeneration. Animals transplanted with GDAs ${ }^{\text {BMP }}$ showed evidence of both initial neuroprotection (as shown by the grid-walk performance at 3 days postsurgery) and continued improvement with time. In contrast, animals transplanted with GDAs ${ }^{\mathrm{CNTF}}$ were indistinguishable at all time points from untreated control SCI rats.

\section{Transplantation of the Wrong Cells can Cause Harm: Causation and Prevention of Neuropathic Pain Syndromes Related to Treatment of SCI}

One of the most critical, but frequently overlooked, aspects of therapeutic development is the identification of means by which particular therapies may actually cause harm. Previous studies of NSCs transplanted into the injured spinal cord have demonstrated that transplantation of these cells can cause neuropathic pain syndromes (allodynia), and that induction of such syndromes could be prevented by genetically modifying NSCs to prevent them from generating astrocytes [108, 109]. As neuropathic pain is one of the most important contributors to a reduced quality of life in spinal injury patients, and has even been suggested to be a major reason for suicide in individuals with $\mathrm{SCI}$, it was of critical importance to determine whether GDA transplantation might also cause such syndromes.

In comparing the effects of both types of GDAs on induction of pain syndromes, we found that transplantation of GDAs ${ }^{\mathrm{CNTF}}$ causes both mechanical allodynia and thermal hyperalgesia, two important components of neuropathic pain syndromes (Fig. 4). Our studies showed that GDAs ${ }^{\mathrm{CNTF}}$ are not alone in causing such syndromes, as GRP cell transplantation also promoted both forms of pain in rats with cervical SCIs. Most importantly, in sharp contrast with the adverse effects of GDA ${ }^{\mathrm{CNTF}}$ and GRP cell transplantation, transplantation of the beneficial $\mathrm{GDAs}^{\mathrm{BMP}}$ did not cause either form of pain syndrome [40].

Our studies of glial cell transplant-induced allodynia, therefore, further demonstrated the usefulness of $\mathrm{GDAs}^{B M \mathrm{P}}$ in repairing the injured spinal cord without such an adverse side effect. At the same time, our studies provide the first identified differentiated neural cell type (i.e., the $\mathrm{GDA}^{\mathrm{CNTF}}$ ) that causes severe pain syndromes following cell transplantation to the injured cord [108, 109]. Importantly, the identification of an astrocyte subtype that can be derived from glial precursor cells by their exposure to CNTF, which is upregulated in the injured adult spinal cord,
Fig. 2 Transplantation of astrocytes generated by exposing GRP cells to BMP (i.e. GDAs ${ }^{\text {BMP }}$ ), but not of the GRP cells themselves, promotes extensive axonal regeneration, tissue reorganization and behavioral recovery following experimental spinal cord injury. (a) transplantation of GDAs ${ }^{\mathrm{BMP}}$ promotes extensive recovery in a volitional foot placement test following transection lesions of the rubrospinal tract. In this behavioral grid-walk (foot placement) assay, animals are first trained until they make a few mistakes. Injury is associated with a sharp increase in the number of mistakes and an absence of recovery, and transplantation of GRP cells does not promote improvements in outcome. In contrast, GDA ${ }^{\mathrm{BMP}}$ transplantation provides initial protection and promotes behavioral recovery so extensive that by the end of 4 weeks many of the transplanted animals cannot be statistically distinguished from nonoperated control animals by this assay. (b) Examination of the distance of regeneration of biotinylated dextran amine (BDA)-labeled axons across the transected spinal cord at 8 days postinjury reveals that in animals transplanted with GDAs ${ }^{\text {BMP }}$, nearly two-thirds of labeled axons grew as far as the injury center and the majority of these grew back into the distal cord, often extending distances of $5 \mathrm{~mm}$ beyond the injury center. In contrast, only a small fraction $(<5 \%)$ of BDA-labeled axons reached the injury center in animals receiving GRP cell transplants. (c) Photomicrographs showing that BDA-labeled axons enter sites of $\mathrm{GDA}^{\mathrm{BMP}}$ transplantation (i.e., the dense red zone in the center) (c) and many of these axons traverse the injury site following GDA ${ }^{\text {BMP }}$ transplantation to re-enter normal tissue. (d) Staining with anti-glial fibrillary acidic protein (GFAP) antibodies reveals the disorganized glial scar tissue that occurs following dorsal column transection, even when GRP cells were transplanted. The unlabeled tissue on the left of the picture contains transplanted GRP cells. (e) In contrast, transplantation of GDAs ${ }^{\mathrm{BMP}}$ is associated with extensive linear re-organization of the host astrocytes. As the GDAs ${ }^{\text {BMP }}$ down-regulate GFAP expression following transplantation, they are not visualized in this figure with anti-GFAP staining. Other stains (not shown) reveal these cells, which occupy the area to the left of the GFAP staining in (e), are linearly organized with the host astrocytes

raises the possibility that some of the neural stem cell or glial precursor cell transplantation therapies, now moving into clinical trials, run a significant risk of causing similar pain syndromes. These observations provide more support for the view that GDAs ${ }^{\text {BMP }}$ represent a particularly promising cell population for repairing the injured spinal cord.

\section{Development of Human Astrocyte Transplantation Therapies}

The next essential step in the development of clinically useful astrocyte transplantation therapies is to determine whether similarly beneficial effects can be obtained with human GDAs $^{\text {BMP }}$ (hGDAs ${ }^{\mathrm{BMP}}$ ). We have recently accomplished this by providing the first human astrocyte capable of promoting extensive repair of SCI [41]. Moreover, our results with human cells reinforce the paradigms established through our work on rodent cells by demonstrating that the same considerations apply to the generation of therapeutically useful cell types from human glial precursor cells. 

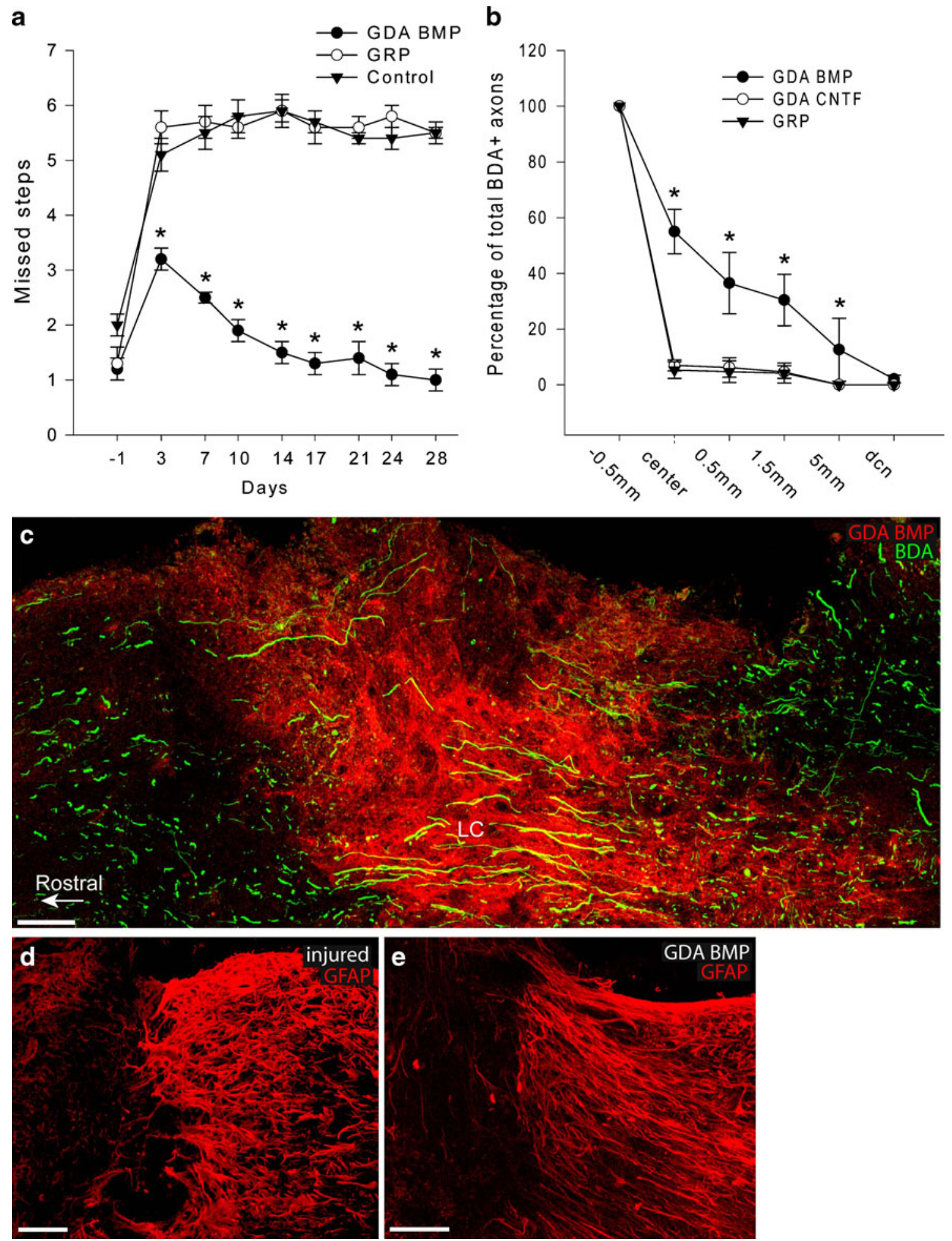

We first found that when human embryonic glial progenitor cells (hGPCs) isolated from spinal cords of 9.5-week-old abortuses were exposed to bone morphogenetic protein-4 (BMP) or CNTF, we induced astrocytes with markedly different phenotypes. Both BMP and CNTF- induced astrocyte populations express GFAP, aquaporin 4, and $\mathrm{S} 100 \beta$, which are three widely used markers of astrocyte differentiation [42, 110-114]. human GDAs ${ }^{\text {BMP }}$ (hGDAs $^{\text {BMP }}$ ) also expressed connexin 43 , glutamate transporter 1, A-kinase anchoring protein-12 (AKAP12), and 
glial-derived neurotrophic factor (GDNF), all of which are expressed in the astroglial lineage [115-117]. In contrast, human astrocytes derived from hGPCs treated with CNTF did not induce expression of glutamate transporter 1, connexin 43, AKAP12, or GDNF. Instead, hGDAs ${ }^{\mathrm{CNTF}}$, but not hGDAs ${ }^{\text {BMP }}$, expressed several antigens commonly expressed in astrocytes generated in response to injury, including Oligodendrocyte transcription factor-2 (Olig2) and the CSPGs brevican, phosphacan, and CSPG4 [59, 68, 118-121]. These results are similar to those obtained with cells derived from the embryonic rat spinal cord and indicate that two distinct types of human astrocyte populations can be generated in vitro from hGPCs, by exposure of precursor cells to BMP or CNTF.

Examination of transplants revealed that both hGDA ${ }^{\text {BMP }}$ and hGDA ${ }^{\mathrm{CNTF}}$ transplants spanned the rostral to caudal extent of injury sites to effectively provide continuous substrates for potential growth of host axons across sites of injury (Fig. 5). However, examination of axonal densities revealed that hGDA ${ }^{\text {BMP }}$ grafts contained many $200 \mathrm{kD}$ neurofilament plus axons, whereas relatively few axons were observed to have penetrated the center of hGDA $^{\text {CNTF }}$ grafts.

Despite the similar ability of transplanted hGDAs ${ }^{\text {BMP }}$ and hGDAs ${ }^{\mathrm{CNTF}}$ to span the rostral to caudal extent of injury sites and migrate into adjacent tissues, only hGDAs ${ }^{\text {BMP }}$ promoted locomotor recovery following transplantation into dorsolateral funiculus (DFL) transection injuries. This injury severs descending, supraspinal axons and causes chronic deficits in both fore-limb and hind-limb motor function [122], which can be detected by the gridwalk/horizontal ladder behavioral test [123]. Although a similar average number of mistakes were seen in each group at 3 days postinjury/transplantation (Fig. 5a), by day 7 the hGDA ${ }^{\mathrm{BMP}}$ group improved from an average $7.7 \pm 0.7$ mistakes per crossing to $4.7 \pm 0.8$, and further improved by day 28 to only $2.4 \pm 0.2$ mistakes, comparable to pre-injury scores. In comparison, at 28 days post injury the untreated injury group and animals receiving $\mathrm{h}^{\mathrm{CNTF}}$ transplants made $6.7 \pm 0.5$ and $6.5 \pm 0.5$ mistakes, respectively. The number of mistakes made by the rats in the hGDA ${ }^{\mathrm{CNTF}}$ group was not significantly different from those in the media-injected DLF-injured control group and did not improve statistically with time.

Furthermore, as for rat-derived cells, we found that predifferentiation of human glial precursor cells was required to obtain significant benefit. Animals that received hGDA $^{\text {BMP }}$ transplants performed significantly better on the grid-walk test than either the hGPC transplanted group or the media-injected control injury group at all time points from 7 to 28 days post injury/transplantation. In contrast, the number of mistakes made by the hGPC-treated group was not different from the untreated injury control group at
Fig. 3 Transplantation of astrocytes generated by exposing GRP cells to BMP (GDAs ${ }^{\mathrm{BMP}}$ ), but not astrocytes generated by exposing GRP cells to CNTF (GDAs ${ }^{\mathrm{CNTF}}$ ), promotes extensive axonal regeneration, tissue reorganization and behavioral recovery following experimental spinal cord injury. (a) Biotinylated dextran amine (BDA)-labeled endogenous, ascending dorsal column axons (green) fail to cross GDA $^{\text {CNTF }}$ transplanted injury sites and instead form dystrophic endings within caudal injury margins. Although a few axons sprout towards the injury center, $\mathrm{BDA}^{+}$axons are rarely detected beyond the injury/transplantation site at 8 days postinjury/transplantation. Scale bar $=200 \mu \mathrm{m}$. (b) In contrast, transplanted GDAs ${ }^{\text {BMP }}$ support extensive axon growth across dorsal column injuries at 8 days after injury/transplantation. Scale bar $=200 \mu \mathrm{m}$. (c) Intra-injury GDAs ${ }^{\mathrm{CNTF}}$ are uniformly glial fibrillary acidic protein $\left(\mathrm{GFAP}^{+}\right)$within acute dorsal column injuries. Note the co-localization (yellow) of human placental alkaline phosphatase (hPAP) (red) with GFAP (green). GDAs ${ }^{\mathrm{CNTF}}$ align host astrocytic processes within injury margins. Survival at 8 days post-injury/transplantation. (d) Graph showing the average number of missed steps per experimental group from 1 day before injury (baseline pre-injury) to 28 days after injury for all GDAtransplanted/dorsolateral funiculus injured rats versus the control-injured animals. GDA ${ }^{\mathrm{BMP}}$-transplanted animals (green) performed significantly better than GDA ${ }^{\mathrm{CNTF}}$-transplanted animals and injured control animals at all postinjury time points $(p<0.05)$. Note that the performance of $\mathrm{GDA}^{\mathrm{CNTF}}$-transplanted animals was not different from untreated control injured rats at all time points (2-way repeated measures analysis of variance; $* p<0.05) . \mathrm{N}=9$ rats per group

all postinjury time points and did not improve statistically with time.

Differences in behavioral recovery were mirrored by marked differences in promotion of neuronal survival within ipsilateral spinal cord gray matter immediately adjacent to sites of injury and even within rostral and caudal gray matter, in which no transplanted hGDAs ${ }^{\text {BMP }}$ were observed. Significant improvements in neuronal survival in multiple laminae were seen in a $1.8-\mathrm{mm}$ length of spinal cord encompassing the injury site of hGDA ${ }^{\mathrm{BMP}}$. treated animals. Combined neuron counts for laminae 4 to 9 showed that hGDA ${ }^{\mathrm{BMP}}$ transplantation promoted increases of $40 \%$ and $32 \%$, in two separate experiments, of surviving neurons compared to untreated injured spinal cords, with significant increases seen in all laminae. Analysis of a region closer to the site of injury, through $750 \mu \mathrm{m}$ of tissue spanning the injury center, revealed notably robust increases in numbers of neurons for lamina 7 (35\% and $32 \%)$ and laminae 8 and $9(70 \%$ and 54\%), which were greater than control injured cords.

\section{Why are GDAs ${ }^{\text {BMP }}$ Beneficial?}

Determination of the exact mechanisms by which any cell type provides benefit after transplantation to the traumatically injured CNS is challenging, given the wide range of possible effects of such procedures, and we would suggest that there are a variety of means by which GDA transplantation contributes to the recovery 

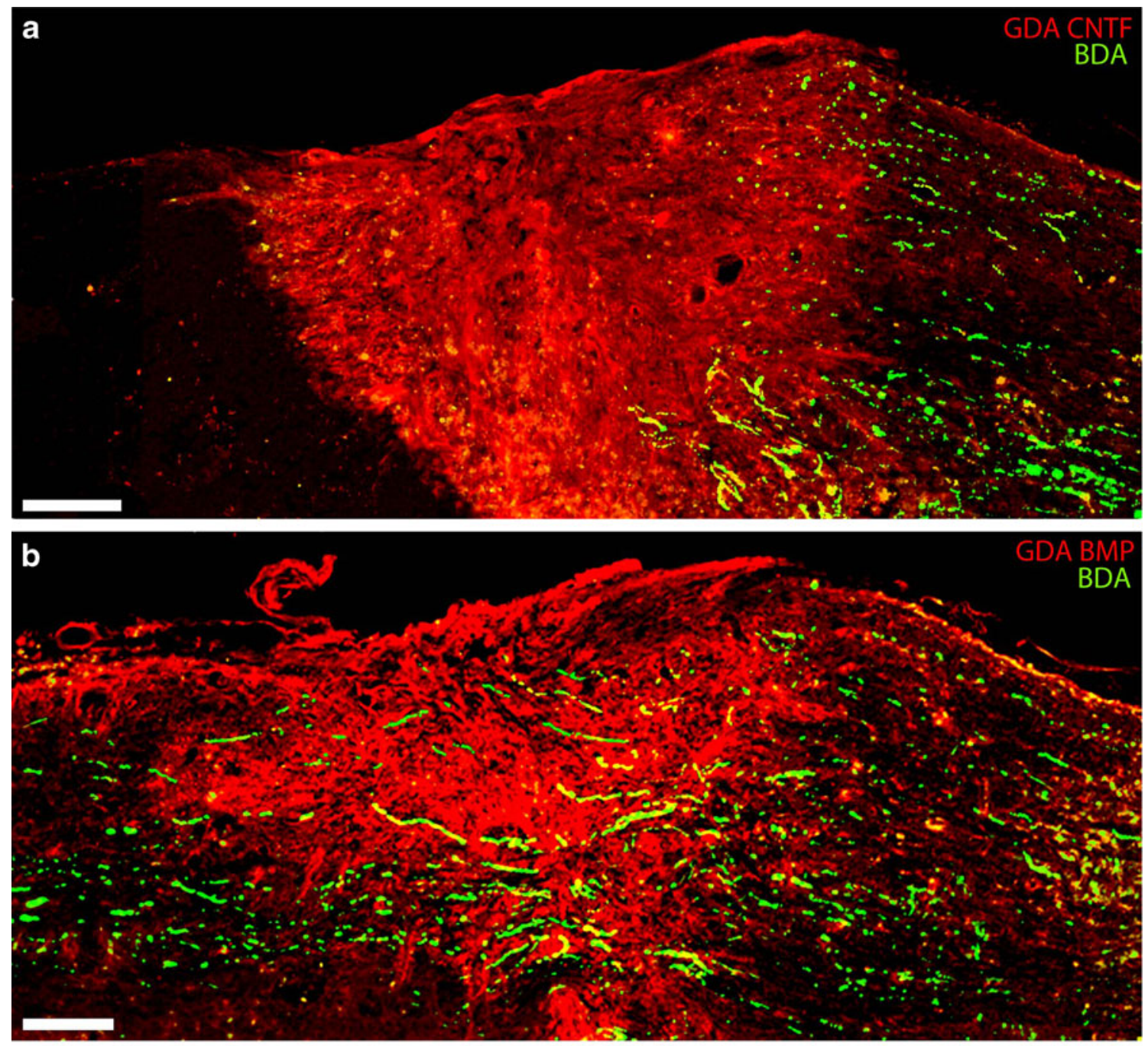

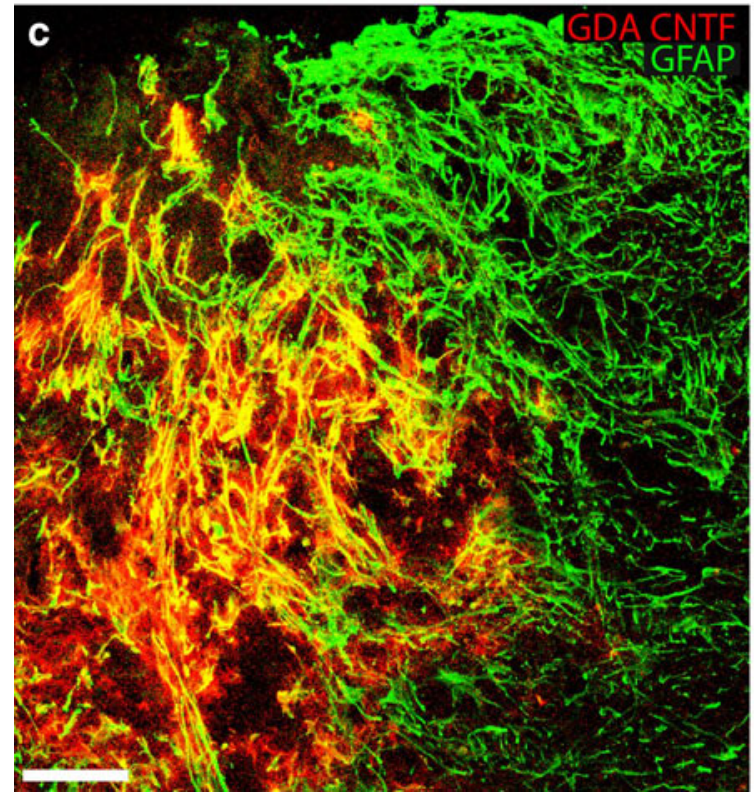

of locomotion observed in our acute SCI experiments. As some recovery of function was already seen 3 days

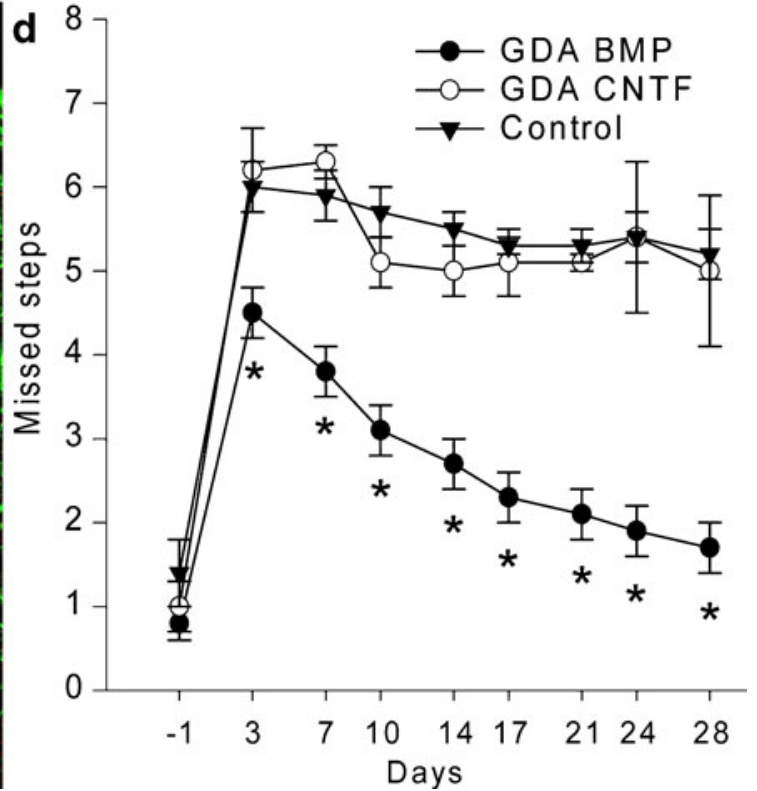

after transplantation of rat GDAs ${ }^{\mathrm{BMP}}$, it seems likely that some benefit occurs as the result of protection of 
Fig. 4 Von Frey filament and hot-plate analysis of mechanical and thermal allodynia. (a) Withdrawal threshold of the right front paw to a mechanical stimulus (force in grams). Measurements were made 2, 3, 4 or 5 weeks after animals received dorsolateral funiculus lesions and were transplanted with GRP cells, GDAs ${ }^{\mathrm{BMP}}$ or GDAs ${ }^{\mathrm{CNTF}}$, or vehicle alone. (b) Latency (in seconds) to paw withdrawal from a heat source. Note that injury alone and GDA ${ }^{\mathrm{BMP}}$ transplantation do not induce statistically significant mechanical or thermal allodynia at any time point. However, the mechanical threshold and latency to withdrawal from a heat source were both significantly lower in animals trans-

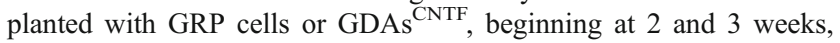
respectively, post-injury/transplantation. Asterisks denote a statistical difference from time-matched control animals (two-way repeated measures, ANOVA, $p<0.05$ ). Error bars represent $1 \mathrm{SD}$. BDA = biotinylated dextran amine; $\mathrm{BMP}=$ biotinylated dextran amine; $\mathrm{CTNF}=$ ciliary neurotrophic factor

endogenous neuronal populations. This would be consistent with our observed rescue of red nucleus neurons from atrophy in our GDA ${ }^{\text {BMP }}$ transplants [39] and extensive rescue of spinal motor neurons in our transplants of hGDAs $^{\text {BMP }}$ [41]. Rescue of red nucleus neurons from atrophy has been achieved previously through provision of brain-derived neurotrophic factor (BDNF) [124]. Ongoing analyses of gene expression in GDAs shows readily detectable levels of BDNF mRNA in GDAs ${ }^{\text {BMP }}$ (C. Pröschel, unpublished observations). In contrast, previous studies indicate that postnatal cortex-derived astrocytes (which have a type-1 morphology and antigenic phenotype) do not make BDNF [42], revealing another advantage of GDAs ${ }^{\mathrm{BMP}}$ and indicating that the antigenic category of type-1 astrocytes [95] in which GDAs were originally placed $[79,80]$ is too broadly defined and needs refinement. The significant increases in behavioral recovery from 3 days onward, however, also suggests that axon regeneration and/or plasticity of connection may have contributed to overall functional recovery. The significantly greater number of neurons with cell body diameters over $20 \mu \mathrm{m}$ in the injured red nucleus of GDA $^{\mathrm{BMP}}$-treated animals at 5 weeks after injury, combined with the further elongation of rubrospinal tract (RST) axons in caudal white matter observed between 8 days and 5 weeks, supports a possible contribution of RST axon growth and plasticity to overall behavioral recovery [39]. However, this too probably only represents a partial component of the contribution of GDAs ${ }^{\text {BMP }}$ to recovery.

The ability of GDAs ${ }^{\text {BMP }}$ to provide benefit to ascending dorsal column and RST axons and to rescue motor neuron survival $[39,41]$ raises the possibility that these astrocytes will also be found to support the recovery of other axon populations relevant to locomotion, such as those in the descending reticulospinal and lateral corticospinal pathways.
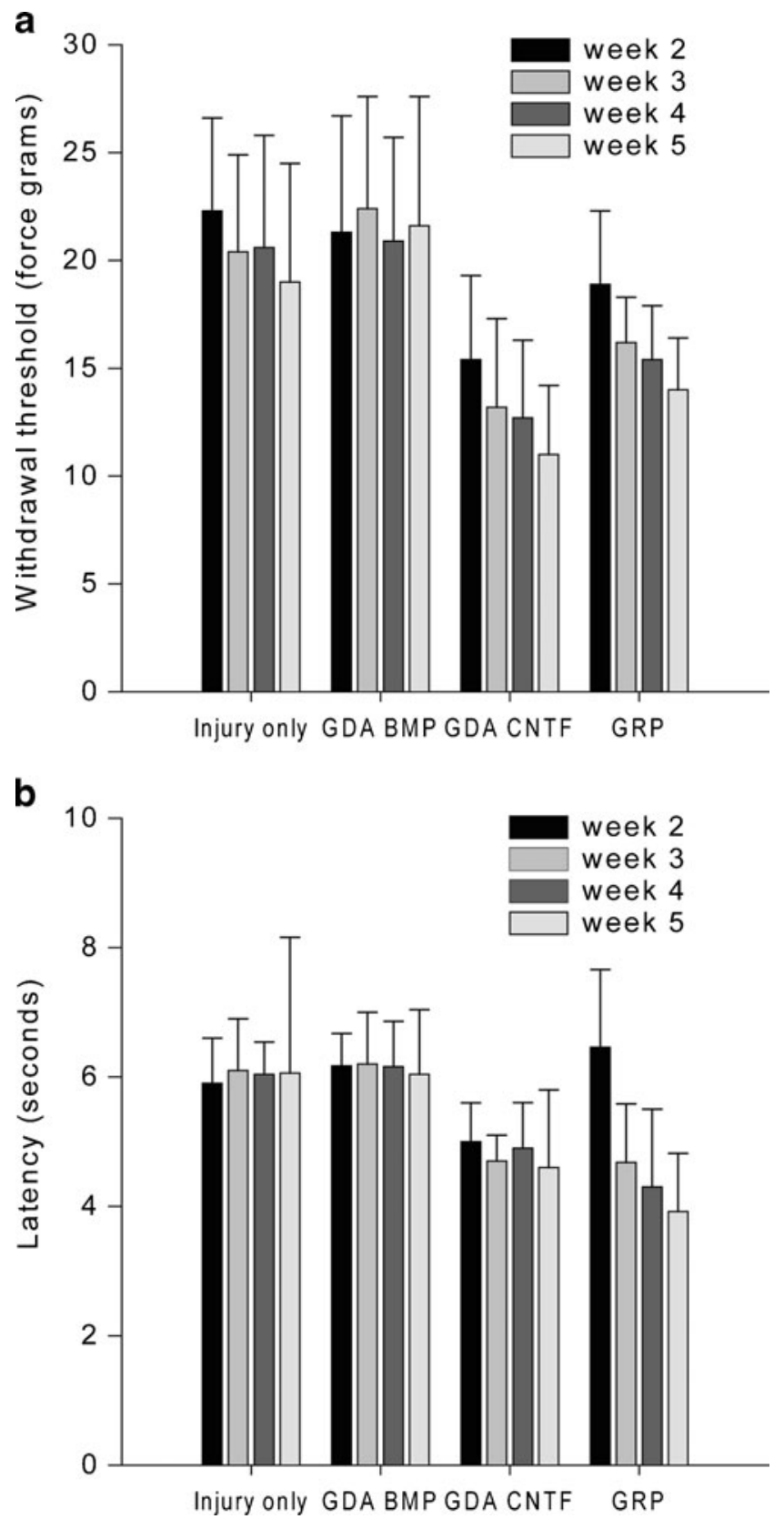

Delayed expression of inhibitory CSPGs associated with GDA $^{\text {BMP }}$ transplantation also may contribute to enabling regenerative axon growth. The absence of neurocan and NG2 immunoreactivity shown by GDAs ${ }^{\text {BMP }}$ within sites of injury indicates that intra-lesion GDAs ${ }^{\mathrm{BMP}}$ may be refractory to signaling molecules known to induce expression of neurocan in neonatal astrocyte cultures [125]. Thus, intralesion GDAs ${ }^{\mathrm{BMP}}$ maintained an axon-growth supportive phenotype with respect to CSPG expression. Moreover, the presence of GDAs ${ }^{\mathrm{BMP}}$ within lesions also modified the host response to injury and resulted in a significant reduction in NG2 expression within injury centers and a delay in neurocan expression at injury margins [39], which together 
may have created a window of opportunity for axons not only to enter, but also to exit the injury site.

We are also particularly intrigued by the ability of $\mathrm{GDAs}^{\mathrm{BMP}}$ to promote/preserve linear tissue organization at sites of injury. Although previous studies have demonstrated that alignment of host astrocytic processes alone is not sufficient to promote axon growth across CNS injuries in the presence of inhibitory CSPGs $[60,126]$, clearly the efficiency of axon growth across an injury site with reduced inhibitor expression will be enhanced if axons are not required to negotiate a maze of misaligned cellular processes that typify glial scar tissue. The fact that a dissociated suspension of GDAs ${ }^{\text {BMP }}$ is able to effect a linear alignment within acute adult spinal cord transection injuries without the addition of an aligned biomatrix suggests that the creation of such tissue organization is a fundamental aspect of the biology of these cells. For larger injuries, however, particularly those found in human patients with severe contusion injuries, it may prove necessary to incorporate GDAs ${ }^{\mathrm{BMP}}$ into an aligned biomatrix to effectively bridge these comparatively large injuries.

The extent to which astrocyte migration is important in providing benefit is unclear in light of some of our results. It is known that astrocytes (or cells that give rise to astrocytes) can effectively migrate into the injured and normal spinal cord [127-129], and it has been suggested that such migration is important to understanding the benefits provided by these cells (for more detail see Okada et al. [23]). However, we have seen protection of neurons even in spinal cord laminae that were not populated by transplanted hGDAs ${ }^{\mathrm{BMP}}$ [41]. Moreover, it is critical to note that in our studies on both rat GDAs ${ }^{\mathrm{BMP}}$ and hGDAs ${ }^{\mathrm{BMP}}$, we have seen that the continued presence of the transplanted astrocytes in the lesion is not necessary to achieve a durable behavioral recovery [39-41]. Such outcomes make it clear that the effects of these transplanted astrocytes on the host tissue is critical to understanding the benefits gained from these cells, a situation very different from the expected dependence of recovery on maintained transplant function in situations in which the transplanted cells are themselves a part of neuronal circuitry or are the generators of new myelin.

\section{What Have We Learned?}

Besides the identification of a novel astrocyte population that appears to have considerable promise as a celltherapeutic tool to promote CNS injury repair, there are several other conclusions/hypotheses we can draw from these findings that we suggest have broader implications for the field of cell therapy as a whole and for neuroscience research in particular.
The first issue of concern is whether injured tissue can optimally induce the differentiation of transplanted precursor cells in a manner that best restores tissue function. Our data indicate there are significant reasons for thinking this is not always the case. In the specific instance of astrocyte generation in the injured spinal cord, the comparatively poor performance of GRP cells, as compared with $\mathrm{GDAs}^{\mathrm{BMP}}$, in promoting repair when transplanted into acute spinal cord injuries suggests that, in this instance, the injured cord is not inducing the generation of optimally useful populations of astrocytes. It is not yet known whether the reason GRP cells are less effective at promoting axon regeneration, protection of neurons, and recovery of locomotor function in SCI rats is due to an absence of factors in the injury site that are required to induce formation of astrocytes, such as GDAs ${ }^{\mathrm{BMP}}$, or whether precursor cells transplanted into acute spinal cord injuries are instead exposed to factors that induce their differentiation along alternative cell lineage pathways that result in cell types that are not supportive of spinal cord repair. In respect to the endogenous precursor cells of the spinal cord, the presence of Olig2+/GFAP + and NG2+/ GFAP+ astrocytes in the injury site $[118,119,121,130$, 131] suggests that these precursor cells are being induced to differentiate into cells that are more akin to GDAs ${ }^{\mathrm{CNTF}}$. Further support for this hypothesis is provided by studies from the Alonso lab [132], indicating that endogenous adult glial progenitors contribute to scar formation at sites of injury via their differentiation into glial scar astrocytes.

If the endogenous precursor cells present in the adult tissue all represent specialized adult-specific type of O-2A progenitor cells [133-135], it may be that they are only capable of differentiating into type-2 astrocytes, which have an antigenic phenotype resembling that of astrocytes generated from spinal cord GRP cells following exposure to CNTF or other gp130 agonists [40, 80].

Regardless of the specific reasons for the failure of GRP cells to provide the degree of benefit provided by $\mathrm{GDAs}^{\mathrm{BMP}}$, the benefits provided by transplantation of predifferentiated GDAs ${ }^{\mathrm{BMP}}$ have been robust in all of our studies [39-41]. Therefore, this is a substantively different paradigm than applies to the repair of demyelinating damage for which it is progenitor cell transplantation that is required to obtain optimal repair, with transplantation of oligodendrocytes themselves being largely ineffective in this regard [136].

In considering the previous issues, however, it is important to stress that we are at the earliest stages of understanding the complexity of the astrocyte-related response to CNS injury. For example, studies of Okada et al. [23] have elegantly demonstrated important beneficial contributions of endogenous astrocytes (and/or their pre- 
cursor cells) to the response to SCIs. Recent studies from the Kessler laboratory [24] have shown that different BMP receptors (BMPR1a and BMPR1b) elicit different effects on gliosis, with BMPR1a promoting an early astrocytic hypertrophy response that appears to be beneficial. BMPR $1 b$, in contrast, appears to be of primary importance in the later generation of reactive astrocytes that play an important role in glial scar formation and progression. Whether these two responses represent still another later of astrocyte complexity, or are related to the biology of the 2 astrocyte populations we have been studying is not yet known, but the possibility is intriguing to consider.

The second conclusion to emerge from our studies is that not all astrocytes are equivalent in their ability to promote repair. Functional heterogeneity in astrocyte populations has been observed for some time, both in vivo and in vitro $[4,5,17,18,137-148]$. It has not been known, however, whether such differences represent different traits of a single astrocyte population or truly distinct cell types generated from different progenitor cells and/or via different signaling mechanisms. In contrast, our studies unequivocally establish that different astrocytes are functionally very different in their effects on SCI repair. Our results further demonstrate that transplantation into the damaged CNS provides a useful approach to the discovery of functional differences between astrocyte populations.

A third lesson that emerges from our studies is that it is critically important to fully define cell populations (preferably at the clonal level) to pursue their development for tissue repair. GRP cells and O-2A progenitor cells are purified on the basis of antigenic phenotype, the timing of development at which they are isolated, and the tissue from which they are isolated, but the antibodies used for their purification are identical $[25,78,80,86]$. Moreover, GRP cells can express the platelet-derived growth factor receptor- $\alpha$, NG2 and Olig2, while still retaining their capacity to generate astrocytes with both type- 1 and type2 characteristics [78] in vitro. It is only by clonal analysis of GRP cells to be certain that one has a homogeneous population of such cells. If the field of cell therapy develops in a manner analogous to the development of pharmaceuticals, it will be increasingly important to demonstrate the absolute purity of the populations to be used for transplantation.

The previously described considerations suggest that too little is presently known to enable reliable generation of optimally beneficial astrocytes from human embryonic stem cells (ESCs) or from induced pluripotent stem cells. The means of preferentially generating GRP cells versus $\mathrm{O}-2 \mathrm{~A}$ progenitor cells from either ESCs or induced pluripotent stem cells have not been identified, and the lack of antigenic markers that distinguish these populations means
Fig. 5 Astrocytes generated by exposing human glial precursor cells (hGPCs) to BMP (hGDAs ${ }^{\text {BMP }}$ ) are robust promoters of axonal regeneration and behavioral recovery, whereas astrocytes generated by exposing GRP cells to CNTF (hGDAs ${ }^{\mathrm{CNTF}}$ ) and hGPCs themselves are not (a-c). Human GPCs grown in fibroblast growth factor-2 (FGF-2) (a) were induced to differentiate into astrocytes using BMP (b) or CNTF (c). Labeling with anti-glial fibrillary acidic protein (GFAP) (Alexa-488) demonstrates that both BMP and CNTF induce differentiation of human glial precursors into glial fibrillary acidic protein (GFAP)-expressing astrocytes, whereas Olig2 expression (Alexa-568) is not seen in hGDAs ${ }^{\mathrm{BMP}}$. Scale bar $=50 \mu \mathrm{m}$. (d, e) Immunostaining for human mitochondrial marker (red channel) of histological cross sections at sites of injury revealed hGDAs ${ }^{\text {BMP }}$ (d) and hGDAs ${ }^{\mathrm{CNTF}}$ (e) transplant masses spanning the dorsal-ventral and lateral-medial margins of injury sites. Co-labeling for neurofilament (NF) (green) and human mitochondrial marker (hMito) (red) shows a markedly higher density of axons within hGDAs ${ }^{\mathrm{BMP}}$-treated injury sites (d) compared to hGDAs ${ }^{\mathrm{CNTF}}$-treated injury sites (e). Survival= 5 weeks post injury/transplantation. Scale bar $=100 \mu \mathrm{m}$. (f) Human GDAs $^{\mathrm{BMP}}$ promote robust locomotor recovery, but hGDAs ${ }^{\mathrm{CNTF}}$ and hGPCs do not. The graph shows the average number of mistakes per experimental group made during grid walk testing of locomotor recovery at 1 day before injury to 28 days after injury. In 2 separate experiments, hGDA ${ }^{\text {BMP }}$ transplanted animals (closed circles) performed significantly better than hGDA ${ }^{\mathrm{CNTF}}$ or hGPC not shown) transplanted animals at all time points from 7 to 28 days postinjury/ transplantation. The performance of hGDA ${ }^{\mathrm{CNTF}}$ or hGPC (not shown) transplanted animals was not significantly different from control injured rats at all time points (2-way repeated measures analysis of variance; *p<0.05). (g) Human GDA ${ }^{\mathrm{BMP}}$ transplantation led to significant increases in numbers of neuronal nuclei-positive $(\mathrm{NeuN}+$ ) neurons counted in a 1.8-mm length of spinal cord encompassing the injury site. Graphs show percentage changes in numbers of NeuN + neurons in laminae 4 to 9 ; laminae 4,5 , and 6; 7, 8 and 9 in spinal cords from animals that received transplants of 9 W2 or 9 W1 hGDAs $^{\mathrm{BMP}}$, hGDAs ${ }^{\mathrm{CNTF}}$, or hGPCs and untreated control injuries

that it is not possible to directly purify either of these populations from induced cultures. Therefore, even though it is possible to generate astrocytes from ESCs, the types of astrocytes are not clear. It will be essential to compare such astrocytes with GDAs ${ }^{\mathrm{BMP}}$ to determine if they are equivalently useful in promoting repair.

The importance of attention to detail is indicated by the recent studies from Fischer et al., in which they also studied the effects of transplantation of human embryonic glial precursor cells and astrocytes generated from them by exposure to BMP [84]. In agreement with our studies, no significant recovery in motor function was seen in animals receiving the human glial precursor cells. In sharp contrast with our studies, however, there was no significant recovery in motor function seen in the animals receiving the hGPCderived astrocytes, and there was also no difference in the ability of either population to promote axonal outgrowth. What could be the explanation for the differences between their studies and those we conducted? Certainly, there were multiple differences in the approaches utilized in these studies as compared with our own. Fischer et al. carried out transplants into contusion injuries, in athymic rats, and 

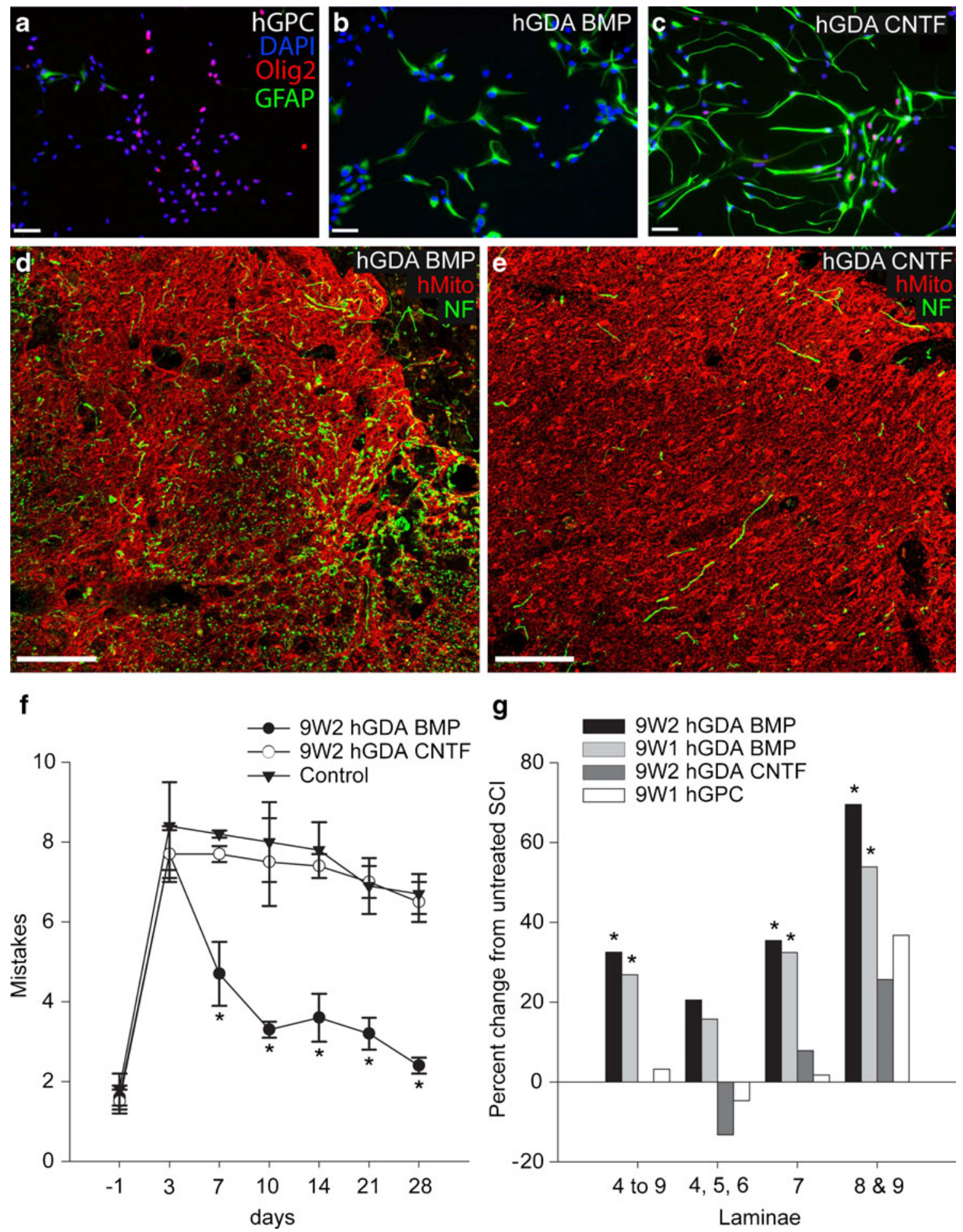

delayed transplantation until 9 days after injury. They also grew cells on different substrates than used in our experiments. Our ongoing studies suggest that it is not these differences, however, that are the critical ones in respect to the study of regeneration. We note, however, that the use of athymic rats may have compromised the ability to

adequately study neuropathic pain syndromes in these animals due to the importance of cells of the immune system in generating these syndromes [149-152]. Finding out what differences are responsible for generating useful astrocytes versus astrocytes that do not provide the robust benefits repeatedly seen in our own studies will be essential 
if we are to develop astrocyte transplantation therapies as a useful approach to CNS repair.

Acknowledgment Our work on astrocyte transplantation therapies has been generously supported by funding from the National Institutes of Health [grant numbers RO1-NS046442, RO1-NS42820], the New York State Department of Health Spinal Injury Research Program grants CO19772, CO20942, CO16889 and C023691, the Christopher and Dana Reeve Foundation, the Lone Star Paralysis Foundation, the Carlson Stem Cell Trust, the CareCure SCI community and other members of the spinal cord injury community. The funders had no role in study design, data collection and analysis, decision to publish, or preparation of previous manuscripts or this manuscript. Full conflict of interest disclosure is available in the electronic supplementary material for this article.

Open Access This article is distributed under the terms of the Creative Commons Attribution Noncommercial License which permits any noncommercial use, distribution, and reproduction in any medium, provided the original author(s) and source are credited.

\section{References}

1. Noble M, Seang JF, Cohen J. Glia are a unique substrate for the in vitro growth of central nervous system neurons. J Neurosci 1984;4:1892-903.

2. Fallon JR. Preferential outgrowth of central nervous system neurites on astrocytes and Schwann cells as compared with nonglial cells in vitro. J Cell Biol 1985;100:198-207.

3. Qian JA, Bull MS, Levitt P. Target-derived astroglia regulate axonal outgrowth in a region-specific manner. Dev Biol 1992;149:278-294.

4. Buard I, et al. Glial cells promote dendrite formation and the reception of synaptic input in Purkinje cells from postnatal mice. Glia 2010;58:538-545.

5. Steinmetz CC, et al. Regional variations in the glial influence on synapse development in the mouse CNS. J Physiol 2006;577 (pt 1):249-261.

6. Learte AR, Hidalgo A. The role of glial cells in axon guidance, fasciculation and targeting. Adv Exp Med Biol 2007;621:156-166.

7. Abbott NJ, Ronnback L, Hansson E. Astrocyte-endothelial interactions at the blood-brain barrier. Nat Rev Neurosci 2006;7:41-53.

8. Araque A, Navarrete M. Glial cells in neuronal network function. Philos Trans R Soc Lond B Biol Sci 2010;365:2375-2381.

9. Bentz K, et al. Neural differentiation of embryonic stem cells is induced by signalling from non-neural niche cells. Cell Physiol Biochem 2006;18:275-286.

10. Fellin T. Communication between neurons and astrocytes: relevance to the modulation of synaptic and network activity. J Neurochem 2009;108:533-544.

11. Fellin T, Carmignoto G. Neurone-to-astrocyte signalling in the brain represents a distinct multifunctional unit. J Physiol 2004;559(pt 1):3-15.

12. Fiacco TA, McCarthy KD. Astrocyte calcium elevations: properties, propagation, and effects on brain signaling. Glia 2006;54:676-690.

13. Freeman MR. Specification and morphogenesis of astrocytes. Science 2010;330:774-778.

14. Giaume C, et al. Astroglial networks: a step further in neuroglial and gliovascular interactions. Nat Rev Neurosci 2010;11:87-99.

15. Haseloff RF, et al. In search of the astrocytic factor(s) modulating blood-brain barrier functions in brain capillary endothelial cells in vitro. Cell Mol Neurobiol 2005;25:25-39.
16. Haydon PG, Carmignoto G. Astrocyte control of synaptic transmission and neurovascular coupling. Physiol Rev 2006;86:10091031.

17. Kimelberg HK. Functions of mature mammalian astrocytes: a current view. Neuroscientist 2010;16:79-106.

18. Kimelberg HK, Nedergaard M. Functions of astrocytes and their potential as therapeutic targets. Neurotherapeutics 2010;7:338 353.

19. Koehler RC, Gebremedhin D, Harder DR. Role of astrocytes in cerebrovascular regulation. J Appl Physiol 2006;100:307-317.

20. Nedergaard M, Ransom B, Goldman SA. New roles for astrocytes: redefining the functional architecture of the brain. Trends Neurosci 2003;26:523-530.

21. Seifert G, Schilling K, Steinhauser C. Astrocyte dysfunction in neurological disorders: a molecular perspective. Nat Rev Neurosci 2006;7:194-206.

22. Simard M, Nedergaard M. The neurobiology of glia in the context of water and ion homeostasis. Neuroscience 2004;129:877-896.

23. Okada S, et al. Conditional ablation of Stat 3 or Socs 3 discloses a dual role for reactive astrocytes after spinal cord injury. Nat Med 2006;12:829-834.

24. Sahni V, et al. BMPR1a and BMPR1b signaling exert opposing effects on gliosis after spinal cord injury. J Neurosci 2010;30:18391855.

25. Groves AK, et al. Repair of demyelinated lesions by transplantation of purified O-2A progenitor cells. Nature 1993;362:453-455.

26. Warrington AE, Barbarese E, Pfeiffer SE. Differential myelinogenic capacity of specific developmental stages of the oligodendrocyte lineage upon transplantation into hypomyelinating hosts. J Neurosci Res 1993;34:1-13.

27. Jeffery $\mathrm{N}$, et al. Behavioural consequences of oligodendrocyte progenitor cell transplantation into experimental demyelinating lesions in the rat spinal cord. Eur. J Neurosci 1999:xx:15081514.

28. Honmou $\mathrm{O}$, et al. Restoration of normal conduction properties in demyelinated spinal cord axons in the adult rat by transplantation of exogenous Schwann cells. J.Neurosci 1996;16:3199-3208.

29. Utzschneider DA, et al. Transplantation of glial cells enhances action potential conduction of amyelinated spinal cord axons in the myelin-deficient rat. Proc Natl Acad Sci USA 1994:xx:5357.

30. Liu S, et al. Embryonic stem cells differentiate into oligodendrocytes and myelinate in culture and after spinal cord transplantation. Proc Natl Acad Sci USA 2000;97:6126-6131.

31. Windrem MS, et al. Progenitor cells derived from the adult human subcortical white matter disperse and differentiate as oligodendrocytes within demyelinated lesions of the rat brain. J Neurosci Res 2002;69:966-975.

32. Windrem MS, et al. Neonatal chimerization with human glial progenitor cells can both remyelinate and rescue the otherwise lethally hypomyelinated shiverer mouse. Cell Stem Cell 2008;2:553-565.

33. Windrem MS, et al. Fetal and adult human oligodendrocyte progenitor cell isolates myelinate the congenitally dysmyelinated brain. Nat Med 2004;10:93-7.

34. Learish $\mathrm{RD}$, et al. Intraventricular transplantation of oligodendrocyte progenitors into a fetal myelin mutant results in widespread formation of myelin. Ann Neurol 1999;46:716-722.

35. Perez-Bouza A, Glaser T, Brustle O. ES cell-derived glial precursors contribute to remyelination in acutely demyelinated spinal cord lesions. Brain Pathol 2005;15:208-216.

36. Cloutier F, et al. Transplantation of human embryonic stem cellderived oligodendrocyte progenitors into rat spinal cord injuries does not cause harm. Regen Med 2006;1:469-479.

37. Brustle O, et al. Embryonic stem cell-derived glial precursors: a source of myelinating transplants. Science 1999;285:754-756. 
38. Zhang SC, Lipsitz D, Duncan ID, Self-renewing canine oligodendroglial progenitor expanded as oligospheres. J Neurosci Res 1998;54:181-190.

39. Davies JE, et al. Astrocytes derived from glial-restricted precursors promote spinal cord repair. J Biol 2006;5:7.

40. Davies JE, et al. Transplanted astrocytes derived from BMP or CNTF treated glial restricted precursors have opposite effects on recovery and allodynia after spinal cord injury. J Biol 2008;7:e24.

41. Davies SJA, et al. Transplantation of specific human astrocytes promotes functional recovery after spinal cord injury. PLoS ONE 2011;6:e17328.

42. Bignami A, et al. Localization of the glial fibrillary acidic protein in astrocytes by immunofluorescence. Brain Res 1972;43:429-435.

43. Brenner M, et al. Mutations in GFAP, encoding glial fibrillary acidic protein, are associated with Alexander disease. Nat Genet 2001;27:117-120.

44. Rodriguez D, et al. Infantile Alexander disease: spectrum of GFAP mutations and genotype-phenotype correlation. Am J Hum Genet 2001;69:1134-1140.

45. Li R, et al. GFAP mutations in Alexander disease. Int J Dev Neurosci 2002;20:259-268.

46. Dietrich J, et al. EIF2B5 mutations compromise GFAP $(+)$ astrocyte generation in vanishing white matter leukodystrophy. Nat Med 2005;11:277-283.

47. Nagai M, et al. Astrocytes expressing ALS-linked mutated SOD1 release factors selectively toxic to motor neurons. Nat Neurosci 2007;10:615-622.

48. Ouyang YB, et al. Overexpression of inducible heat shock protein 70 and its mutants in astrocytes is associated with maintenance of mitochondrial physiology during glucose deprivation stress. Cell Stress Chaperones 2006;11:180-186.

49. Seifert G, Carmignoto G, Steinhauser C. Astrocyte dysfunction in epilepsy. Brain Res Rev 2010;63:212-221.

50. Bradford J, et al. Expression of mutant huntingtin in mouse brain astrocytes causes age-dependent neurological symptoms. Proc Natl Acad Sci U S A 2009;106:22480-22485.

51. Bradford $\mathrm{J}$, et al. Mutant huntingtin in glial cells exacerbates neurological symptoms of Huntington disease mice. J Biol Chem 2010;285:10653-10661.

52. Xu L, Zeng LH, Wong M. Impaired astrocytic gap junction coupling and potassium buffering in a mouse model of tuberous sclerosis complex. Neurobiol Dis 2009;34:291-299.

53. Maezawa I, et al. Rett syndrome astrocytes are abnormal and spread MeCP2 deficiency through gap junctions. J Neurosci 2009;29:5051-5061.

54. Cui $\mathrm{M}$, et al. The organic cation transporter-3 is a pivotal modulator of neurodegeneration in the nigrostriatal dopaminergic pathway. Proc Natl Acad Sci U S A 2009;106:80438048.

55. Rappold PM, Tieu K. Astrocytes and therapeutics for Parkinson's disease. Neurotherapeutics 2010;7:413-423.

56. Seifert G, et al. Enhanced relative expression of glutamate receptor 1 flip AMPA receptor subunits in hippocampal astrocytes of epilepsy patients with Ammon's horn sclerosis. J Neurosci 2004;24:1996-2003.

57. Windle WF, Clemente CD, Chambers WW. Inhibition of formation of a glial barrier as a means of permitting a peripheral nerve to grow into the brain. $J$ omp Neurol 1952;96:359-369.

58. McKeon RJ, Höke A, Silver J. Injury-induced proteoglycans inhibit the potential for laminin-mediated axon growth on astrocytic scars. Exp Neurol 1995;136:32-43.

59. McKeon RJ, Jurynec MJ, Buck CR. The chondroitin sulfate proteoglycans neurocan and phosphacan are expressed by reactive astrocytes in the chronic CNS glial scar. J Neurosci 1999;19:10778-10788.
60. Davies SJ, Field PM, Raisman G. Regeneration of cut adult axons fails even in the presence of continuous aligned glial pathways. Exp Neurol 1996;142:203-216.

61. Davies S, et al. Robust regeneration of adult sensory axons in degenerating white matter of the adult rat spinal cord. J Neurosci 1999;19:5810-5822.

62. Groves AK, et al. The characterization of astrocyte cell lines that display properties of glial scar tissue. Dev Biol 1993;159:87104.

63. Buss A, et al. NG2 and phosphacan are present in the astroglial scar after human traumatic spinal cord injury. BMC Neurol 2009;9:32.

64. Morgenstern DA, Asher RA, Fawcett JW. Chondroitin sulphate proteoglycans in the CNS injury response. Prog Brain Res 2002; $137: 313-332$.

65. Sandvig A, et al. Myelin-, reactive glia-, and scar-derived CNS axon growth inhibitors: expression, receptor signaling, and correlation with axon regeneration. Glia 2004;46:225251.

66. Jones LL, Margolis RU, Tuszynski MH. The chondroitin sulfate proteoglycans neurocan, brevican, phosphacan, and versican are differentially regulated following spinal cord injury. Exp Neurol 2003;182:399-411.

67. Krautstrunk M, et al. Increased expression of the putative axon growth-repulsive extracellular matrix molecule, keratan sulphate proteoglycan, following traumatic injury of the adult rat spinal cord. Acta Neuropathol 2002;104:592-600.

68. Tang X, Davies JE, Davies SJ. Changes in distribution, cell associations, and protein expression levels of NG2, neurocan, phosphacan, brevican, versican V2, and tenascin-C during acute to chronic maturation of spinal cord scar tissue. J Neurosci Res 2003;71:427-444.

69. Ard MD, et al. Growth and degeneration of axons on astrocyte surfaces: effects on extracellular matrix and on later axonal growth. Glia 1993;9:248-259.

70. Wang LC, et al. Astroglial differentiation is required for support of neurite outgrowth. J Neurosci 1994;14(5 pt 2):3195-3207.

71. Lu SY, et al. Effect of fetal striatal and astrocyte transplants into unilateral excitotoxin-lesioned striatum. J Neural Transplant Plast 1993;4:279-287.

72. Bradbury EJ, et al. Astrocyte transplants alleviate lesion induced memory deficits independently of cholinergic recovery. Neuroscience 1995;65:955-972.

73. Joosten EA, Veldhuis WB, Hamers FP. Collagen containing neonatal astrocytes stimulates regrowth of injured fibers and promotes modest locomotor recovery after spinal cord injury. J Neurosci Res 2004;77:127-142.

74. McCarthy K, Vellis JD. Preparation of seperate astroglial and oligodendroglial cultures from rat cerebral tissue. J Cell Biol 1980;85:890-902.

75. Noble M, Murray K. Purified astrocytes promote the in vitro division of a bipotential glial progenitor cell. EMBO J 1984;3:2243-2247.

76. Smith GM, et al. Maturation of astrocytes in vitro alters the extent and molecular basis of neurite outgrowth. Dev Biol 1990;138:377-390.

77. Rao MS. Multipotent and restricted precursors in the central nervous system. Anat Rec 1999;257:137-148.

78. Noble M, Pröschel C, Mayer-Proschel M. Getting a GR(i)P on oligodendrocyte development. Dev Biol 2004;265:33-52.

79. Rao M, Mayer-Pröschel M. Glial restricted precursors are derived from multipotent neuroepithelial stem cells. Dev Biology 1997;188:48-63.

80. Rao M, Noble M, Mayer-Pröschel M. A tripotential glial precursor cell is present in the developing spinal cord. Proc Natl Acad Sci U S A 1998;95:3996-4001. 
81. Mayer-Pröschel M, et al. Isolation of lineage-restricted neuronal precursors from multipotent neuroepithelial stem cells. Neuron 1997;19:773-785.

82. Maragakis NJ, et al. Glutamate transporter expression and function in human glial progenitors. Glia 2004;45:133-143.

83. Walczak P, et al. Human glial-restricted progenitors survive, proliferate, and preserve electrophysiological function in rats with focal inflammatory spinal cord demyelination. Glia 2011;59:499-510.

84. Jin Y, et al. Transplantation of human glial restricted progenitors and derived astrocytes into a contusion model of spinal cord injury. J Neurotrauma 2011;28:(in press).

85. Hill CE, et al. Acute transplantation of glial restricted precursor cells into spinal cord contusion injuries: survival, differentiation and effects on lesion environment and axonal regeneration. Exp Neurol 2004;190:289-310.

86. Herrera $\mathrm{J}$, et al. Embryonic-derived glial-restricted precursor cells (GRP cells) can differentiate into astrocytes and oligodendrocytes in vivo. Exp. Neurol 2001;171:11-21.

87. Cao Q, et al. Functional recovery in traumatic spinal cord injury after transplantation of multineurotrophin-expressing glialrestricted precursor cells. J Neurosci 2005;25:6947-6957.

88. Nout YS, et al. Glial restricted precursor cell transplant with cyclic adenosine monophosphate improved some autonomic functions but resulted in a reduced graft size after spinal cord contusion injury in rats. Exp Neurol 2011;227:159-171.

89. Alexanian AR, et al. Transplantation of human glial-restricted neural precursors into injured spinal cord promotes functional and sensory recovery without causing allodynia. Cytotherapy 2010;13:61-68.

90. Wu DC, et al. Glial cell response: A pathogenic factor in Parkinson's disease. J Neurovirol 2002;8:551-558.

91. Lepore AC, Fischer I. Lineage-restricted neural precursors survive, migrate, and differentiate following transplantation into the injured adult spinal cord. Exp Neurol 2005; 194:230-242.

92. Sandrock W, et al. Isolation, characterization and preclinical development of human glial-restricted progenitor cells for treatment of neurological disorders. Regen Med 2010;5:381-394.

93. Mujtaba J, et al. Lineage restricted precursors can be isolated from both the mouse neural tube and cultured ES cells. Dev Biol 1999;214:113-127.

94. Dietrich J, Noble M, Mayer-Proschel M. Characterization of A2B5+ glial precursor cells from cryopreserved human fetal brain progenitor cells. Glia 2002;40:65-77.

95. Raff MC, et al. Two types of astrocytes in cultures of developing rat white matter: differences in morphology, surface gangliosides, and growth characteristics. J Neurosci 1983;3:1289-1300.

96. Raff MC, Miller RH, Noble M. A glial progenitor cell that develops in vitro into an astrocyte or an oligodendrocyte depending on the culture medium. Nature 1983;303:390-396.

97. Raff MC, Abney ER, Miller RH. Two glial cell lineages diverge prenatally in rat optic nerve. Dev Biol 1984;106:53-60

98. Strathmann FG, Wang X, Mayer-Proschel M. Identification of two novel glial-restricted cell populations in the embryonic telencephalon arising from unique origins. BMC Dev Biol 2007;7:33.

99. Mayer M, Bhakoo K, Noble M. Ciliary neurotrophic factor and leukemia inhibitory factor promote the generation, maturation and survival of oligodendrocytes in vitro. Development 1994;120:142-153.

100. Barres B, et al. Ciliary neurotrophic factor enhances the rate of oligodendrocyte generation. Mol Cell Neurosci 1996;8:146-156.

101. Marmur R, et al. Differentiation of oligodendroglial progenitors derived from cortical multipotent cells requires extrinsic signals including activation of gp130/LIFbeta receptors. J Neurosci 1998;18:9800-9811.
102. Espinosa de los Monteros A, Zhang M, De Vellis J. O2A progenitor cells transplanted into the neonatal rat brain develop into oligodendrocytes but not astrocytes. Proc Natl Acad Sci U S A 1993;90:50-54.

103. Blakemore WF, et al. Modelling large areas of demyelination in the rat reveals the potential and possible limitations of transplanted glial cells for remyelination in the CNS. Glia 2002;38:155-168.

104. Keirstead HS, et al. Human embryonic stem cell-derived oligodendrocyte progenitor cell transplants remyelinate and restore locomotion after spinal cord injury. J Neurosci 2005;25:4694-4705.

105. Gregori N, et al. The tripotential glial-restricted precursor (GRP) cell and glial development in the spinal cord: Generation of bipotential oligodendrocyte-type-2 astrocyte progenitor cells and dorsal-ventral differences in GRP cell function. J Neurosci 2002;22:248-256.

106. Hill CE, et al. Transplantation of glial restricted precursor cells into acute spinal cord contusion injuries. Soc Neurosci Abs 2001;xx:xx-xx.

107. Mitsui T, et al. Transplantation of neuronal and glial restricted precursors into contused spinal cord improves bladder and motor functions, decreases thermal hypersensitivity, and modifies intraspinal circuitry. J Neurosci 2005;25:96249636.

108. Hofstetter CP, et al. Allodynia limits the usefulness of intraspinal neural stem cell grafts; directed differentiation improves outcome. Nat Neurosci 2002;8:346-353.

109. Macias MY, et al. Pain with no gain: allodynia following neural stem cell transplantation in spinal cord injury. Exp Neurol 2006;201:335-348

110. Gömöri E, et al. Fetal development of membrane water channel proteins aquaporin-1 and aquaporin- 4 in the human brain. Int. J Dev Neurosci 2006;24:295-305.

111. Haglid KG, et al. Cellular and subcellular distribution of the S100 protein in rabbit and rat central nervous system. J Neurosci Res 1976;2:175-91.

112. Ludwin SK, Kosek JC, Eng LF The topographical distribution of S-100 and GFA proteins in the adult rat brain: an immunohistochemical study using horseradish peroxidase-labelled antibodies. J Comp Neurol 1976;165:197-207.

113. Rash JE, et al. Direct immunogold labeling of aquaporin-4 in square arrays of astrocyte and ependymocyte plasma membranes in rat brain and spinal cord. Proc Natl Acad Sci U S A 1998;95:11981-11986.

114. Badaut J, et al. Distribution of Aquaporin 9 in the adult rat brain: preferential expression in catecholaminergic neurons and in glial cells. Neuroscience 2004;128:27-38.

115. Ochalski PA, et al. Connexin-43 in rat spinal cord: localization in astrocytes and identification of heterotypic astro-oligodendrocytic gap junctions. Neuroscience 1997;76:931945.

116. Lee SS, et al. Characterization of the two genes differentially expressed during development in human fetal astrocytes. Yonsei Med J 2003;44:1059-1068.

117. Rothstein JD, et al. Localization of neuronal and glial glutamate transporters. Neuron 1994;13:713-725.

118. Cassiani-Ingoni R, et al. Cytoplasmic translocation of Olig2 in adult glial progenitors marks the generation of reactive astrocytes following autoimmune inflammation. Exp Neurol 2006;201:349 358.

119. Chen Y, et al. The basic helix-loop-helix transcription factor olig2 is critical for reactive astrocyte proliferation after cortical injury. $\mathrm{J}$ Neurosci 2008;28:10983-10989.

120. Massey JM et al. Increased chondroitin sulfate proteoglycan expression in denervated brainstem targets following spinal 
cord injury creates a barrier to axonal regeneration overcome by chondroitinase $\mathrm{ABC}$ and neurotrophin-3. Exp Neurol 2008;209:426-445.

121. Zhao JW, et al. Astrocytes and oligodendrocytes can be generated from NG2+ progenitors after acute brain injury: intracellular localization of oligodendrocyte transcription factor 2 is associated with their fate choice. Eur J Neurosci 2009;29:1853-1869.

122. Muir GD, Whishaw IQ. Red nucleus lesions impair overground locomotion in rats: a kinetic analysis. Eur J Neurosci 2000;12:1113-1122.

123. Schucht $P$, et al. Anatomical correlates of locomotor recovery following dorsal and ventral lesions of the rat spinal cord. Exp Neurol 2002;176:143-153.

124. Kobayashi NR, et al. BDNF and NT-4/5 prevent atrophy of rat rubrospinal neurons after cervical axotomy, stimulate GAP-43 and Talpha1-tubulin mRNA expression, and promote axonal regeneration. J Neurosci 1997;17:9583-9595.

125. Asher RA, et al. Neurocan is upregulated in injured brain and in cytokine-treated astrocytes. J Neurosci 2000;20:2427-2438.

126. Davies SJ, et al. Regeneration of adult axons in white matter tracts of the central nervous system. Nature 1997;390:680-683.

127. Bernstein JJ, Goldberg WJ. Rapid migration of grafted cortical astrocytes from suspension grafts placed in host thoracic spinal cord. Brain Res 1989;491:205-211.

128. Bernstein JJ, Goldberg WJ. Grafted fetal astrocyte migration can prevent host neuronal atrophy: comparison of astrocytes from cultures and whole piece donors. Restor Neurol Neurosci 1991;2:261-270.

129. Goldberg WJ, Bernstein JJ. Transplant-derived astrocytes migrate into host lumbar and cervical spinal cord after implantation of E14 fetal cerebral cortex into adult thoracic spinal cord. J Neurosci Res 1987;17:391-403.

130. Buffo A, et al. Expression pattern of the transcription factor Olig2 in response to brain injuries: implications for neuronal repair. Proc Natl Acad Sci USA 2005;102:18183-18188.

131. Magnus T, et al. Evidence that nucleocytoplasmic Olig2 translocation mediates brain-injury-induced differentiation of glial precursors to astrocytes. J Neurosci Res 2007;85:2126-2137.

132. Alonso G. NG2 proteoglycan-expressing cells of the adult rat brain: possible involvement in the formation of glial scar astrocytes following stab wound. Glia 2005;49:318-338.

133. Wolswijk G, Noble M. Identification of an adult-specific glial progenitor cell. Development 1989;105:387-400.

134. Wolswijk G, Riddle PN, Noble M. Coexistence of perinatal and adult forms of a glial progenitor cell during development of the rat optic nerve. Development 1990;109:691-698.

135. Wolswijk G, Riddle PN, Noble M. Platelet-derived growth factor is mitogenic for O-2A $\mathrm{A}^{\text {adult }}$ progenitor cells. Glia 1991;4:495-503.
136. Crang AJ, Gilson J, Blakemore WF. The demonstration by transplantation of the very restricted remyelinating potential of post-mitotic oligodendrocytes. J Neurocytol 1998;27:541-553.

137. Autillo-Touati A, et al. Region-specific neuro-astroglial interactions: ultrastructural study of the in vitro expression of neuronal polarity. J Neurosci Res 1988;19:326-342.

138. Rousselet A, et al. In vitro regulation of neuronal morphogenesis and polarity by astrocyte-derived factors. Dev Biol 1990;137:33-45.

139. Rousselet A, et al. Rat mesencephalic neurons in cuture exhibit different morphological traits in the presence of media conditioned on mesencephalic or striatal astroglia. Dev Biol 1988;129:495-504.

140. Oberheim NA, et al. Astrocytic complexity distinguishes the human brain. Trends Neurosci 2006;xx:547-553.

141. Wang DD, Bordey A. The astrocyte odyssey. Prog Neurobiol 2008;86:342-367.

142. Hewett JA. Determinants of regional and local diversity within the astroglial lineage of the normal central nervous system. J Neurochem 2009;110:1717-1736.

143. Garcia-Marques J, et al. Different astroglia permissivity controls the migration of olfactory bulb interneuron precursors. Glia 2010;58:218-230.

144. Horii-Hayashi N, et al. Chondroitin sulfate demarcates astrocytic territories in the mammalian cerebral cortex. Neurosci Lett 2010;483:67-72.

145. White RE, McTigue DM, Jakeman LB. Regional heterogeneity in astrocyte responses following contusive spinal cord injury in mice. J Comp Neurol 2010;518:1370-1390.

146. Zhang Y, Barres BA. Astrocyte heterogeneity: an underappreciated topic in neurobiology. Curr Opin Neurobiol 2010;20:588594.

147. Fitting S, et al. Regional heterogeneity and diversity in cytokine and chemokine production by astroglia: differential responses to HIV-1 Tat, gp120, and morphine revealed by multiplex analysis. J Proteome Res 2010;9:1795-1804.

148. Matyash V, Kettenmann H. Heterogeneity in astrocyte morphology and physiology. Brain Res Rev 2010;63:2-10.

149. Mika J, et al. Minocycline reduces the injury-induced expression of prodynorphin and pronociceptin in the dorsal root ganglion in a rat model of neuropathic pain. Neuroscience 2010;165:1420-1428.

150. Scholz J, Woolf CJ. The neuropathic pain triad: neurons, immune cells and glia. Nat Neurosci 2007;10:1361-1368.

151. Vallejo R, et al. The role of glia and the immune system in the development and maintenance of neuropathic pain. Pain Pract 2010;10:167-184.

152. Watkins LR, Maier SF. Beyond neurons: evidence that immune and glial cells contribute to pathological pain states. Physiol Rev 2002;82:981-1011. 